\title{
CHILDREN'S UNDERSTANDING OF THE COMMUTATIVE LAW OF ADDITION
}

\author{
VICENTE BERMEJO and PURIFICACIÓN RODRIGUEZ
}

Complutense University and Autonome University, Madrid, Spain

\begin{abstract}
This study analyzes the bases that support the comprehension and development of the commutative law of addition. We presented two commutative tasks (compare sums and find the unknown addend) to 72 children from 5 to 8 years of age. Within each task we varied the presence/absence of the result, and the kind-of-addend. In general, our results show that children focus mainly on the addends in judging the equivalence between two commuted pairs. Equally, the errors and strategies analysis offers evidence of the children's inclination to focus on the addends, although older children also center on the results, especially in some conditions. Finally, we tentatively suggest a five level model of understanding of commutativity.
\end{abstract}

\section{Introduction}

Nine years ago Baroody and Gannon (1984) were surprised by the scarcity of research done on the commutativity principle (its development, use, links, etc.). Today we can confirm a very similar situation. However, we think that this topic is worthy of more research. Following the formal definition of commutativity $(a+b=b+a)$, it seems adequate for assessing children's knowledge of this law to analyze how they achieve the coordination of the addends order and the sum or result. To integrate these two components children have to (a) consider simultaneously the addends of the two commuted pairs, and (b) admit the equivalence of the results without solving the additive operations. In effect, it is not sufficient for children to make reference exclusively to the outcome, since the numerical equivalence does not necessarily involve an understanding of the irrelevance of the order of the addends, in the same way that the exclusive concern for the addends does not necessarily imply an understanding of the equivalence of the results (see Baroody \& Gannon, 1984).

Address for correspondence: V. Bermejo, Departamento Psicología Evolutiva y Educación, Universidad Complutense de Madrid, Campus de Samosaguas, E-28023, Madrid, Spain. 


\section{Theoretical and Empirical Background}

As pointed out, the literature relative to this topic is scarce. However, we can outline two main theoretical approaches to the study of commutativity: (1) one which ties in the knowledge of the commutative law with the additive operation, considering it necessary to have a certain level of understanding of addition prior to the acquisition of commutativity (e.g., Briars \& Larkin, 1984; Carpenter, 1986; Riley, Greeno \& Heller, 1983; Weaver, 1982); and (2) another which suggests that knowledge of addition and commutativity is at least acquired separately, that is, following different courses (e.g., Baroody, 1982; Baroody \& Gannon, 1984; Baroody \& Ginsburg, 1986; Baroody, Ginsburg \& Waxman, 1983; Bermejo \& Rodríguez, 1991, 1992, in press; Rodríguez, 1992).

According to the first approach children must have a binary understanding of addition (i.e., combine two sets of cardinality $a$ and $b$ to form a set of cardinality c) to be able to comprehend commutativity, being insufficient a unary understanding (i.e., conceptualize the addition as a change of state because the starting set becomes larger) (Weaver, 1982). In this view knowledge of commutativity presupposes the understanding, at least implicitly, of the part-whole relationship (i.e., scheme that smooths children's difficulties in determining which are the relations between the addends and the sums). Besides, this conceptual development brings about a greater elaboration of children's additive strategies (e.g., enables them to use the strategy of starting the counting from the largest addend disregarding the order of the addends) (e.g., Briars \& Larkin, 1984; Carpenter, 1986; Riley 1983).

In contrast, proponents of the second approach suggest that children's comprehension of commutativity does not depend, at least at the beginning, on the binary understanding of addition nor on the knowledge of the part-whole relationship, but on both the interest to reduce performance demands (i.e., to save cognitive effort) or/and on more general conceptual improvement - that, in turn, might originate the use of certain strategies. Wagner and Walters' (1982) claim might be interpreted as - skill generates understanding, since the acquisition of some arithmetical facts (e.g., $2+3=3+2$ ) initiates in the child's repeated experience with counting.

From an empirical point of view, work concerning the study of commutativity usually is not focused on its understanding per se, leaving many questions unsolved. For example, the nature and size of the addends have been proved to be an important factor in the first arithmetical acquisitions of children, however, a review of the available literature shows the lack of contrasted data regarding its incidence on commutativity. In effect, Ginsburg (1982) pointed out that primary school children seemed to understand commutativity only with small sets, whereas Baroody (1982) found that even preschoolers could appreciate commutativity in larger sets. Likewise, there is a complete lack of evidence regarding the nature of the addends (i.e., concrete vs abstract) in the understanding of commutativity.

What is more important is the emphasis that some authors (e.g., Baroody \& Gannon, 1984; Baroody \& Ginsburg, 1986) put on the fact that children affirm that two commuted pairs are equivalent attending to the result (whole) instead of attending to the addends. Likewise, they consider that the result plays an important role in solving children's "logically inconsistent views" (i.e., disregarding the order of 
the addends with a unary understanding of addition), since it should enable them to discover the commutative law. This criterion, that stresses the role played by the result in the understanding of commutativity, seems to agree with the following definition: "the order of the addends does not affect the result of the sum", less so with formal definition: " $a+b=b+a$ ".

An alternative explanation of the relevance granted to the result might come from the specification of the links between the additive strategies and commutativity. Baroody (1982) and Baroody and Gannon (1984) found that some children use unsophisticated additive strategies (e.g., count-all with concrete objects) and understand commutativity, while others employ complex strategies (e.g., count-on from larger), showing little concern for the order of the addends, without assuming that the result would be the same. Therefore, if the discovery of commutativity depends on the use of the result of the sum, it will not be tied to a binary understanding of addition. That is why Baroody and collaborators suggest that the discovery of commutativity depends on children's appreciation of the equivalence in the results of problems with commuted pairs. However, Resnick and Neches (1984) argue against this point, since they claim that children do not arrive at the knowledge of commutativity by simply comparing the outcomes of two different problems. According to these authors the discovery of commutativity is related to the child's capacity to remember something about the resolution processes, that is, the addends. From our point of view, this conception would correspond to a more elaborate or full knowledge of commutativity, while Baroody and collaborators' approach would refer mainly to the first levels of commutativity understanding.

Finally, Baroody and Gannon's work (1984) follows the existence of three levels in the acquisition of commutativity: (1) Initially, "reversed addends are psychologically different problems", so that $3+2$ is interpreted as "three and two more", while $2+3$ means for young children "two and three more". The sums will be different. (2) "A primitive notion of commutativity" or protocommutativity (i.e., the order in which the numbers are added does not affect the correctness of the addition, though the results could be different). (3) Commutativity "in a mathematical sense", which supposes a binary conception of addition as well as a focus on the outcome of addition. The protocommutativity level seems to be linked to a unary conception of addition, resembling Weaver's (1982) pseudocommutativity.

This brief review makes it possible to observe that within the two theoretical approaches mentioned above a certain additive competence is considered as necessary. Nevertheless, while for some authors a specific level of comprehension is indispensable to give commutativity conceptual meaning, for others it would be enough to have the capacity to find the outcome of the addition either with a unary or binary conception of addition, regardless of whether or not the children are able to understand the several possible part-whole relationships between the numbers. Our hypothesis is that the relevance of the result when judging the equivalence constitutes a first important developmental moment. This would then lead to an order-of-the-addends/result coordination characterizing the full understanding of the commutative law. 


\section{Method}

\section{Subjects}

The subjects were 72 children from a public school in Madrid, distributed between three groups of 24 subjects. These children came from middle class backgrounds and were selected at random. The first group was composed of preschool children from second year, whose ages ranged from 5 to 6 years ( $M$ : 5 years and 6 months); the second group was formed by children from the first course of EGB (Basic General Education) between 6 and 7 years of age ( $M: 6$ years and 4 months); and, finally, the third group was made up of children from the second course of EGB, whose ages ranged between 7 and 8 years ( $M: 7$ years and 6 months). None of these subjects have received formal instruction about commutativity.

\section{Material and Experimental Procedure}

The material employed were two sets of exercises each written on twelve sheets that contained the tasks as well as a pencil and an eraser to execute the tests.

With regard to the empirical procedure, there were 24 commuted pairs that were presented twice, with and without the sum or result. The result was always allocated to the first addition of the commuted pair, the most difficult to execute if children decided to operate since the larger set was assigned to the second addend (see Table 1).

Table 1

List of the Trials Corresponding to each Experimental Condition

Presence of the result

Compare sums

Number facts greater than ten

$$
\begin{array}{lr}
8+11=19 & 11+8 \\
5+8=13 & 8+5 \\
6+14=20 & 14+6
\end{array}
$$

Number facts

$$
\begin{array}{ll}
3+6=9 & 6+3 \\
3+4=7 & 4+3 \\
2+7=9 & 7+2
\end{array}
$$

$8+11$

$5+8$

$6+14$

$11+8$

$8+5$

$14+6$

Circles + numbers

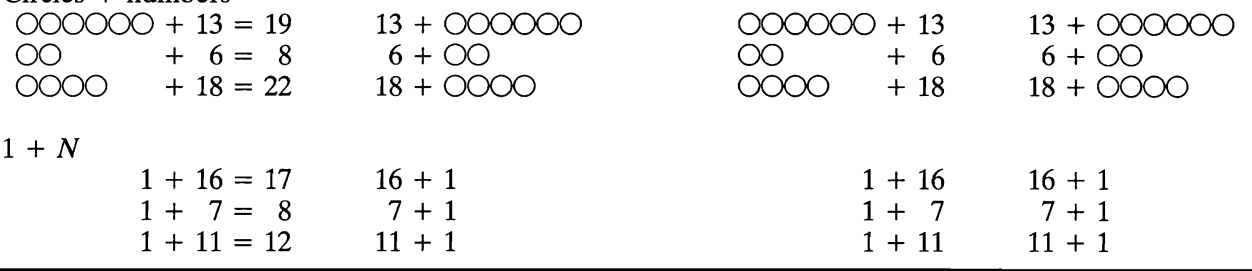


List of the Trials Corresponding to each Experimental Condition

Presence of the result

Find the unknown addend

Number facts greater than ten

$\begin{array}{lr}4+15=19 & 15+- \\ 7+9=16 & 9+ \\ 8+12=20 & 12+\end{array}$

Number facts

$$
\begin{aligned}
& 2+8=10 \\
& 4+5=9 \\
& 2+6=8
\end{aligned}
$$

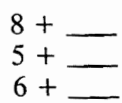

$15+$

$9+$

\begin{tabular}{|c|c|c|c|}
\hline $\begin{aligned} 00000000+16 & =24 \\
000+5 & =8 \\
000000000+14 & =23\end{aligned}$ & $\begin{array}{c}16+ \\
5+\square \\
14+\square\end{array}$ & $\begin{array}{cc}00000000 & +16 \\
000 & +5 \\
000000000 & +14\end{array}$ & $\begin{array}{c}16+ \\
5+- \\
14+\square\end{array}$ \\
\hline $\begin{array}{l}1+12=13 \\
1+6=7 \\
1+14=15\end{array}$ & $\begin{array}{c}12+ \\
6+- \\
14+\end{array}$ & $\begin{array}{l}1+12 \\
1+6 \\
1+14\end{array}$ & $\begin{array}{r}12+ \\
6+ \\
14+\end{array}$ \\
\hline
\end{tabular}

$12+$

Circles + numbers

The children carried out two commutativity tasks one corresponding to the verification and the other to the production situation respectively: (a) compare sums: this task implied a verification process, since children only had to determine whether two subjects in the problem did or did not have an equivalent number of objects from the comparison of the commuted pairs, and explain the reasons on which they based their responses. For instance, "Luis has these candies and Pedro has these. Do they have the same number of candies?".

$$
\begin{array}{cc}
\text { Luis } & \text { Pedro } \\
1+16 & 16+1
\end{array}
$$

(b) Find the unknown addend: this task involved a production process, since the child himself had to build the answer. More precisely, two numerical additions were presented to children within an equalize problem and then they were requested to find the missing addend in the second addition of the commuted pair. As an example, "Cesar has these marbles and Juan has these. How many marbles does Juan need to have the same number of marbles as Cesar?".

$$
\begin{array}{cc}
\text { Cesar } & \text { Juan } \\
1+12 & 12+
\end{array}
$$

We employed four kinds of addends: (1) $1+N$, (2) circles + numbers, (3) number facts, and (4) number facts greater than ten (see Table 1). The order of presentation of 
the three trials corresponding to each type of addend was determined at random and remained constant for all the children.

As shown in Table 1, the tests were arranged as follows: presence vs absence of the result (whole) in one of the two commuted pairs, production situation vs verification situation, and addends with an easily retrievable answer ( $1+N$ and number facts) vs addends with a hardly retrievable answer. The reasons why the condition "presence of the result" in one of the two commuted pairs is taken into consideration are mainly three. First, this factor allows us to analyze the role played by the outcome and the addends in children's understanding of commutativity. From our point of view, the presence of the result could increase the difficulty of the tasks (at least with young children and larger numbers) since children might be inclined to carry out the comparisons attending to the result (the whole) instead of attending to the addends (the parts). Second, the presence of the result in one of the two commuted pairs will permit us to discriminate empirically perceptual answers, based on the presence of the same numbers and mathematical symbols in each commuted pair, from other kinds of commutativity responses, since the condition in which the result is absent in both commuted pairs might be overestimating children's competence. And third, to prevent changes in children's additive counting strategies during the experimental situation imposing extremely high performance demands that hinder their reasoning, to the extent of ignoring that $7+2$ and $7+2$ (i.e., the inverted addition of the commuted pair $2+7$ as a result of the application of an advanced strategy, consisting of starting from the larger addend) are the "same" or "equivalent" pairs.

With regard to the commutativity tasks (compare sums vs find the unknown addend), children have to judge the equivalence between two commuted pairs, but in the "unknown addend" task they have to construct this equivalence by filling in the second pair (i.e., determining which is the second addend). This fact could induce children to focus on the addends instead of the sums, making this task easier than the compare sums task, although in light of the data provided by other research about mathematical concepts (e.g., Gelman \& Meck, 1983, 1986; Miller, Perlmutter \& Keating, 1984), a verification situation is usually easier than a production situation. In other words, these kind of tasks will allow us to see whether children's performance on commutativity is better when they focus especially on the addends rather than on the sums.

Finally, the literature on children's first arithmetical acquisitions reveals that the kind and size of the addends markedly influences children's performances. That is why we present four different kinds of tasks, expecting that the differences among the four kinds of addends will depend on whether children respond attending to the addends or to the sums of the commuted pairs. In effect, if they focus on the addends there should be a similar level of attainment for the four types of addends, and this should be better for the addends with an easily retrievable answer if they centered on the results. Likewise, the addends presented in a concrete manner (i.e., number + circles) will probably make more evident the commuted nature of the addends. It is therefore possible for children who focus on the addends to obtain better results in the concrete than in the numerical tasks.

The tests were administered individually without time limitations, but there was a week in between the two blocks. During the first session, half of the children within each group solved the tasks in which the results were present, while the other half first carried 
out the tasks in which the results were not present. In the second session we followed the same procedure, except that the order of presentation of the tasks was reversed. The subjects were assigned at random to each of the blocks. These two sessions were designed to avoid an excessively long time of testing that would have tired the children, and also to favor the experimental control of the effects of order.

All the tasks were read aloud by the experimenter to avoid, on the one hand, some of the proposed numbers being too difficult to identify in their written form, especially in the case of younger children, and on the other, to prevent children's level of reading skill, most likely lower in preschoolers than in school children, playing an active part in the process of understanding the tasks. Likewise, throughout the two sessions the children's performances were videotaped to allow a close analysis of their behavior.

An incomplete counterbalancing procedure was used to control the order effects in the presentation of the tasks (i.e., find the unknown addend and compare sums) and addends. To this end, an order of eight combinations was randomly obtained from the two tasks and the four kinds of addends. The subjects were randomly assigned to each of the eight resulting orders. Finally, the children's responses were scored as correct when they accurately indicated the number of marbles needed in the task of finding the missing addend affirming the equivalence between the two commuted sets, and when they answered "yes" and justified their response in the task of comparing sums.

\section{Results and Discussion}

In this section we will first present and discuss the results of the quantitative analysis of the data. Then we will analyze the different kinds of errors committed by children, and finally we will present the strategies used by children in the different tasks.

\section{Quantitative Analysis}

The mixed ANOVA 3 (Group: I: preschool vs II: first course of EGB vs III: second course of EGB) $\times 2$ (Result: presence vs absence of the result) $\times 2$ (Task: compare sums vs find the unknown addend) $\times 4$ (Addend: $1+N$ vs circles + numbers vs numerical facts vs numerical facts greater than ten) with repeated measures in the last three factors and carried out with the BMDP2V, showed significant main effects for all the factors considered: group $\left(F_{2,69}=12.21, p<.01\right)$, presence/absence of the result $\left(F_{1,69}=56.91, p<.01\right)$, task $\left(F_{1,69}=4.41, p<.05\right)$, and kind of addend $\left(F_{3,207}=3.87, p<.05\right)$. Thus, as may be observed in Table 2 , children's overall success rate did increase as they got older, though none of the pairwise comparisons done with the Newman-Keuls test were significant. Contrary to what was expected from other research about mathematical concepts (e.g., Gelman \& Meck, 1983, 1986), children's performance was better when faced with the task of finding the unknown addend than with that of comparing sums; thus confirming our hypothesis relative to the fact that children's responses are mainly based on the addends. Likewise, the higher rate of correct responses in absence of the result may have been due to the fact that the children's responses were mainly focused on the addends, and/or, as indicated below, 
to the fact that the presence of the result provided the possibility of determining more precisely the children's commutative competence. Finally, the kind of addend used also influenced children's success but neither the comparisons carried out with the Newman-Keuls test nor the Scheffé contrast between the easily and hardly retrieved answers were significant (see the meaning of these results below in the analysis of the interaction).

Table 2

Average and Standard Deviation (in brackets) of Correct Responses

\begin{tabular}{lcccccc}
\hline & \multicolumn{3}{c}{ Absence of results } & \multicolumn{3}{c}{ Presence of results } \\
& Group I & Group II & Group III & Group I & Group II & Group III \\
\hline $\begin{array}{l}\text { Compare sums } \\
1+N\end{array}$ & 1.9 & 2.4 & 2.7 & 0.7 & 1.0 & 2.0 \\
& $(1.3)$ & $(1.2)$ & $(0.8)$ & $(0.8)$ & $(1.5)$ & $(1.2)$ \\
Circles + numbers & 2.5 & 2.6 & 2.7 & 0.9 & 1.4 & 2.1 \\
& $(1.3)$ & $(1.2)$ & $(0.8)$ & $(0.6)$ & $(1.5)$ & $(1.4)$ \\
Numerical facts & 2.0 & 2.5 & 2.7 & 0.5 & 1.1 & 2.1 \\
& $(1.4)$ & $(1.1)$ & $(0.8)$ & $(1.1)$ & $(1.4)$ & $(1.4)$ \\
Numerical facts & 2.1 & 2.6 & 2.7 & 0.6 & 1.2 & 2.1 \\
greater than ten & $(1.3)$ & $(1.1)$ & $(0.8)$ & $(1.2)$ & $(1.5)$ & $(1.4)$ \\
& & & & & & \\
Find the unknown addend & 2.3 & 2.6 & 2.8 & 0.8 & 1.4 & 2.5 \\
1 $N$ N & $(1.1)$ & $(1.1)$ & $(0.6)$ & $(1.3)$ & $(1.5)$ & $(1.1)$ \\
& 2.3 & 2.7 & 2.7 & 1.0 & 2.0 & 2.3 \\
Circles + numbers & $(1.1)$ & $(0.7)$ & $(0.7)$ & $(1.3)$ & $(1.4)$ & $(1.1)$ \\
& 2.2 & 2.7 & 2.9 & 0.9 & 1.4 & 2.6 \\
Numerical facts & $(1.1)$ & $(0.8)$ & $(0.6)$ & $(1.3)$ & $(1.5)$ & $(1.1)$ \\
& 2.1 & 2.7 & 2.9 & 0.7 & 1.4 & 2.4 \\
Numerical facts & $(1.4)$ & $(0.8)$ & $(0.6)$ & $(1.3)$ & $(1.5)$ & $(1.2)$ \\
greater than ten & & & & & &
\end{tabular}

Maximum possible score is 3 .

This analysis also showed a significant interaction between group and presence/absence of the result $\left(F_{2,69}=3.77, p<.05\right)$, as well as between group and addends $\left(F_{6,207}=2.70\right.$, $p<.05)$. With regard to the former interaction, we carried out an analysis with simple comparisons between the different groups in presence and in absence of the result. A significant difference was only found between preschoolers and older children when the result was present $\left(F_{1,69}=4,54, p<.05\right)$, whereas in absence of the result none of the contrasts made were significant. The overall level of attainment in the three groups diminished when the result was present, evidencing the existence of two patterns: (a) group II resembled group I in that the drop of their success rate is noteworthy; and (b) group III did not register such a pronounced decrease in its levels of success as did groups I and II. Thus, in line with the aforementioned prediction, the presence of the result makes the subjects' task more difficult, especially in the case of the younger children. This drop in the level of performance seems to arise from at least two facts: the result would induce children to focus on the outcomes instead of focusing on the addends, as was predicted; and second, this task permits us to discriminate between responses that are purely perceptive from those that are not, that is - as will be shown in the analysis of the errors - some children reject the equivalence of the commuted pairs because in one of them the result is not present. 
The interaction between group and kind of addends was analyzed by the interaction contrasts between groups, considering the addends simultaneously by twos. Results evidenced only significant contrasts between the addends $1+N$ and circles + numbers for groups I vs III $\left(F_{1,207}=4.2, p<.05\right)$, and II vs III $\left(F_{1,207}=5.4, p<.05\right)$. Performance within each group is quite homogeneous along the different kinds of addends, except for the circles + numbers addend in which the performance improved for groups I and II. This is probably due to the fact that this situation makes the commuted nature of the addends more evident, thus making the children's task easier especially in the case of the younger children. According to our hypothesis the homogenity shown along the other kinds of addends would confirm that, in general, children's responses are focused at the addends and not in the outcome of the additions.

To conclude, the quantitative analysis makes evident the important role played by the addends in judging the equivalence of commuted pairs. These results are in accordance with the position taken by Resnick and Neches (1984), which stresses the role played by the addends in understanding the commutative law.

\section{Analysis of Errors}

We undertake the error analysis starting with the compare sums task both in absence and presence of the result, to describe afterwards the errors committed by children in the task of finding the unknown result also in absence and presence of the result.

Table 3

Percentages of the Different Types of Errors Committed by Children in the Compare Sums Task

\begin{tabular}{|c|c|c|c|c|c|c|c|c|c|c|c|c|c|}
\hline \multirow[b]{2}{*}{ Errors } & & \multicolumn{4}{|c|}{ Group I } & \multicolumn{4}{|c|}{ Group II } & \multicolumn{4}{|c|}{ Group III } \\
\hline & & $1^{*}$ & 2 & 3 & 4 & 1 & 2 & 3 & 4 & 1 & 2 & 3 & 4 \\
\hline $\begin{array}{l}\text { (1) Point out the } \\
\text { absence of the } \\
\text { result }\end{array}$ & $\begin{array}{l}\text { Absence } \\
\text { Presence }\end{array}$ & $\overline{51.8}$ & $\overline{68.6}$ & $\overline{57.6}$ & $\overline{59.7}$ & $\overline{68.8}$ & $\overline{64.1}$ & $\overline{76.6}$ & $\overline{71.4}$ & $\overline{66.7}$ & $\overline{81.8}$ & $\overline{57.1}$ & $\overline{47.8}$ \\
\hline $\begin{array}{l}\text { (2) Lack of the } \\
\text { equal sign and } \\
\text { of the result }\end{array}$ & $\begin{array}{l}\text { Absence } \\
\text { Presence }\end{array}$ & $\overline{7.1}$ & $\overline{11.8}$ & $\overline{8.5}$ & $\overline{12.3}$ & - & - & - & - & - & - & - & - \\
\hline $\begin{array}{l}\text { (3) The sums of } \\
\text { the two additions } \\
\text { are different }\end{array}$ & $\begin{array}{l}\text { Absence } \\
\text { Presence }\end{array}$ & $\overline{28.6}$ & $\overline{5.9}$ & $\overline{10.2}$ & $\overline{8.8}$ & $\overline{12.5}$ & $\overline{18}$ & $\overline{10.6}$ & $\overline{7.1}$ & $\overline{20.8}$ & $-\overline{18.2}$ & $\overline{28.6}$ & $\overline{26.1}$ \\
\hline $\begin{array}{l}\text { (4) The addends } \\
\text { are reversed }\end{array}$ & $\begin{array}{l}\text { Absence } \\
\text { Presence }\end{array}$ & $\begin{array}{l}100 \\
7.1\end{array}$ & $\begin{array}{c}100 \\
11.8\end{array}$ & $\begin{array}{l}100 \\
13.6\end{array}$ & $\begin{array}{l}100 \\
10.5\end{array}$ & $\begin{array}{l}100 \\
18.8\end{array}$ & $\begin{array}{c}100 \\
10.3\end{array}$ & $\begin{array}{l}83.3 \\
12.8\end{array}$ & $\begin{array}{l}90 \\
21.4\end{array}$ & $\begin{array}{l}100 \\
12.5\end{array}$ & $\begin{array}{l}100 \\
--\end{array}$ & $\begin{array}{l}100 \\
14.3\end{array}$ & 100 \\
\hline $\begin{array}{l}\text { (5) The addends } \\
\text { are reversed and } \\
\text { the result is not } \\
\text { present }\end{array}$ & $\begin{array}{l}\text { Absence } \\
\text { Presence }\end{array}$ & $\overline{5.4}$ & $\overline{2}$ & $\overline{10.2}$ & $\overline{8.8}$ & - & $\overline{5.1}$ & - & - & - & - & - & $\overline{26.1}$ \\
\hline $\begin{array}{l}\text { (6) A random } \\
\text { response }\end{array}$ & $\begin{array}{l}\text { Absence } \\
\text { Presence }\end{array}$ & - & - & - & - & - & $\overline{2.6}$ & 16.7 & 10 & - & - & - & - \\
\hline
\end{tabular}

${ }^{*} 1,1+N ; 2$, circles + numerals; 3 , numerical facts; 4 , numerical facts greater than ten. 


\section{Compare Sums Tasks in Absence of the Result}

As shown in Table 3, we registered two types of errors: rejecting the equivalence adducing that the addends were reversed (type 5 in Table 3); and responding with a random number (type 6). The first type of error appeared in the three experimental groups (see Table 3), whereas the second type occurred rarely and only in group II.

\section{Compare Sums Task with the Result Present}

Here we observed six types of errors (see Table 3): (1) perceptual errors in which children compared both operations in order to determine that they were not equivalent because of the absence of a result; (2) or the absence of the equal sign in one of the operations; (3) rejecting the equivalence because the results of both operations were different; (4) errors related to the addends, when children stressed the reversed nature of the addends in the two operations to justify that the results were unequal; (5) a kind of mixed error in which children pointed out the presence of the result in one of the operations as well as the reversed nature of the addends; and (6) random responses.

As shown in Table 3 the most common type of error committed by children regardless of the kind of addend corresponded to the perceptual category. This indicates that children limited themselves to checking whether both additions contained the same terms.

\section{Finding the Unknown Addend Task in Absence of the Result}

There were four types of errors (see Table 4): responding with the result of adding the two numbers of the complete addition (type 1 in Table 4); repeating the known addend indicated in the second addition (type 3); a random number (type 4); and repeating the first numerical addition (i.e., when faced with the problem $4+5$ vs $5+$, children responded by writing down $5+\underline{4+5}$ ) (type 6).

Preschool children's errors consisted mainly in repeating the amounts indicated in the problem. This behavior was similar to that found for addition tasks with the unknown in the first addend (Bermejo \& Rodríguez, 1990, in press; Rodríguez, 1992). More precisely, this behavior revealed that children focused on the perception of the addends,

Table 4

Percentages of the Different Types of Errors Committed by Children in the Find the Unknown Addend Task

\begin{tabular}{|c|c|c|c|c|c|c|c|c|c|c|c|c|c|}
\hline \multirow[b]{2}{*}{ Errors } & & \multicolumn{4}{|c|}{ Group I } & \multicolumn{4}{|c|}{ Group II } & \multicolumn{4}{|c|}{ Group III } \\
\hline & & $1^{*}$ & 2 & 3 & 4 & 1 & 2 & 3 & 4 & 1 & 2 & 3 & 4 \\
\hline \multirow{4}{*}{$\begin{array}{l}\text { (1) Write down: } \\
\text { (a) the result of } \\
\text { the first addition } \\
\text { (b) the result and } \\
\text { sign of the first } \\
\text { addition }\end{array}$} & Ahsence & 313 & $\ldots$ & 30 & 143 & 667 & 167 & 571 & 50 & 100 & 714 & 100 & 100 \\
\hline & Presence & 59.6 & 60.4 & 52 & 44.4 & 33.3 & 44 & 38.5 & 36.9 & 50 & 37.5 & 33.3 & 26.7 \\
\hline & Absence & - & - & - & - & - & - & - & - & - & - & - & - \\
\hline & Presence & - & 6.3 & - & - & - & - & - & - & - & - & - & - \\
\hline
\end{tabular}


Table 4 (continued)

Percentages of the Different Types of Errors Committed by Children in the Find the Unknown Addend Task

\begin{tabular}{lllllllllllll}
\hline & \multicolumn{3}{c}{ Group I } & \multicolumn{4}{c}{ Group II } & \multicolumn{3}{c}{ Group III } \\
Errors & $1^{*}$ & 2 & 3 & 4 & 1 & 2 & 3 & 4 & 1 & 2 & 3 & 4 \\
\hline
\end{tabular}

(2) Reject the equivalence because:

(a) the addends are reversed

(b) the result is not present

(3) Write down the known addend

(4) A random number

(5) The first pair result plus the known addend of the second pair
Absence Presence Absence Presence $\overline{5.8} \quad \overline{63} \quad \overline{6}$ $\begin{array}{llll}6.3 & 6 & 5.6 & -\end{array}$ $-\quad-\quad-$

$\begin{array}{lll}37.5 & 37.5 & 40\end{array}$

Absence Presence

Absence Presence

$31.3 \quad 43.8$ $\begin{array}{ll}5.8 & 8.3\end{array}$

Absence Presence

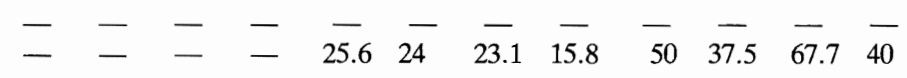

(6) Copy:
(a) the first pair
Absence
- $-\frac{}{6}$

$\begin{array}{rr}\overline{3} .7 & - \\ 14.3 & - \\ 5.6 & -\end{array}$
(b) the first pair
Presence without the result
Presence
$-\quad 18.8 \quad 15$

(7) Write down:
(a) the result and some of the addends
Absence
$-\quad-\quad-\quad-$
$\overline{27.8} \quad \overline{23.1}-$
$\begin{array}{cccccc}-30.8 & 39.5 & - & - & - & - \\ - & - & - & - & - & - \\ - & - & - & - & - & -\end{array}$
(b) the result, some of the addends and the
Absence Presence
$\overline{7.7} \overline{8.3}-\overline{1.9}$ equal sign

${ }^{*} 1,1+N ; 2$, circles + numerals; 3 , numerical facts; 4 , numerical facts greater than ten.

but since these appeared in a reversed order, children either responded with the known addend or copied the first numerical addition.

\section{Finding the Unknown Addend Task with the Result Present}

As shown in Table 4, children's errors were classified into seven types: (1) responding with the result of the first operation with or without the equal sign; (2) indicating correctly the unknown addend without accepting the equivalence of the two operations, due to the reversed order of the addends or to the lack of result in one of the operations; (3) answering with the known addend; (4) a random number; (5) adding the result of the incomplete numerical addition and the first addend of the complete addition; (6) establishing the unknown addend as equivalent to the complete addition independently of the presence or absence of the result; and (7) responding with the result of the first operation, sometimes including one of the addends and even the equal sign. 
The errors committed by preschool and first course EGB children (group II) consisted mainly in responding with the first type of error, as well as with the seventh type of error (see Table 4). These children behaved as if the equal sign was unimportant in determining the meaning of the amounts involved in an additive operation. Our findings share much in common with those of other studies done about the equal sign (Baroody \& Ginsburg, 1983; Behr, Erlwanger \& Nichols, 1976; De Corte \& Verschaffel, 1981; Hiebert, 1989; Kieran, 1981), showing that children do not grant to this symbol an equivalence meaning, but seem rather to misinterpret it as an operator symbol meaning "add up to" or "make a total of". Although in group III the first type of error still remained, children mainly committed the error in which they added the first term of the second addition to the result of the complete addition.

\section{Analysis of the Strategies}

We consider the strategies employed by children in the two commutativity tasks separately, and in both cases, in absence and in presence of the result.

\section{Compare Sums Task in Absence of Result}

For this kind of task we observed four different types of strategies (see Table 5). First, strategies focusing on the addends, where children indicated that both additions were equivalent, claiming that: one of the addends was present in both operations (type 1 in Table 5); both addends were the same in the two additions (i.e., for the $4+6$ vs $6+4$ problem, children explained while pointing at the numbers: "yes, they've got the same (i.e., meaning the same result) because, you see, here there are 4 and here too, 6 and 6") (type 2); or, finally, the addends were reversed (type 3). Second, strategies centered on the result, concluding it was the same for both operations, once children had solved both sums (type 4), just one (type 5) or none (type 6). Third, strategies in which children explicitly described the commutative law of addition (type 7); and fourth, the strategy in which children indicated that both the addends and the mathematical signs were the same in the two commuted pairs (type 8).

As can be observed in Table 5, these results showed that for the three experimental groups, children made use mainly of the addends to justify the equivalence. In fact, they were likely to claim that both addends were the same (an average percentage of $65.33,69.35$, and 37.1 of trials for groups I, II and III respectively). Nevertheless, in the second course of EGB (group III) a noticeable percentage of children (i.e., $37.5 \%$ of the subjects) first solved one of the additions to indicate afterwards that the two additions reached the same total, without calculating the other sum too (an average of $32.19 \%$ of trials). The strategy in which children explicitly mentioned the commutative law of addition (i.e., " $6+4$ is the same as $4+6$, the result is the same") was employed exclusively by children from group III (an average of $7.19 \%$ of trials). Finally, the strategy in which children pointed out that both the addends and the mathematical signs were the same in the two commuted pairs was exclusively used by the preschoolers' group (an average of $7.65 \%$ of trials). This is a kind of perceptual strategy, since children limited themselves to test the presence of the same terms in the two operations. 
Table 5

Percentages of the Strategies Employed in the Compare Sums Task

\begin{tabular}{|c|c|c|c|c|c|c|c|c|c|c|c|c|c|}
\hline \multirow{2}{*}{ Strategy } & & \multicolumn{4}{|c|}{ Group I } & \multicolumn{4}{|c|}{ Group II } & \multicolumn{4}{|c|}{ Group III } \\
\hline & & $1^{*}$ & 2 & 3 & 4 & 1 & 2 & 3 & 4 & 1 & 2 & 3 & 4 \\
\hline \multirow{2}{*}{$\begin{array}{l}\text { (1) One of the } \\
\text { addends is equal }\end{array}$} & Absence & 14.9 & 60 & - & 5.9 & 15.5 & 24.2 & 10 & 12.9 & 9.1 & 25.8 & 4.5 & 4.5 \\
\hline & Presence & 25 & 57.1 & - & - & 12.5 & 30.3 & 12 & 10 & - & 10 & - & - \\
\hline \multirow[t]{2}{*}{ (2) Equal addends } & Absence & 70.2 & 33.3 & 81.3 & 76.5 & 63.9 & 64.5 & 66.7 & 82.3 & 31.8 & 34.8 & 31.8 & 50 \\
\hline & Presence & 56.3 & 28.6 & 76.9 & 80 & 37.5 & 33.3 & 52 & 50 & - & 10 & 5.9 & 6.1 \\
\hline \multirow{2}{*}{$\begin{array}{l}\text { (3) Reversed } \\
\text { addends }\end{array}$} & Absence & 2.1 & - & 6.3 & 5.9 & 5.1 & - & 5 & - & 4.5 & 4.5 & 13.6 & 9.1 \\
\hline & Presence & - & 14.3 & - & 20 & 12.5 & 18.2 & 12 & 10 & 18.8 & 6 & 17.7 & 18.4 \\
\hline \multirow{2}{*}{$\begin{array}{l}\text { (4) The same result, } \\
\text { solving both } \\
\text { additions }\end{array}$} & Absence & - & 6.7 & - & - & - & - & - & - & - & - & - & - \\
\hline & Presence & - & - & - & - & - & - & 一 & - & - & - & - & - \\
\hline \multirow{2}{*}{$\begin{array}{l}\text { (5) The same result, } \\
\text { computing one } \\
\text { addition }\end{array}$} & Absence & - & - & - & - & 15.5 & 11.3 & 18.3 & 4.8 & 36.4 & 24.2 & 40.9 & 27.3 \\
\hline & Presence & 6.4 & - & - & - & 25 & 18.2 & 12 & 20 & 6.3 & 8 & - & 2 \\
\hline \multirow{2}{*}{$\begin{array}{l}\text { (6) The same result } \\
\text { without computing }\end{array}$} & Absence & - & - & - & - & - & - & - & - & 9.1 & 4.5 & - & 4.5 \\
\hline & Presence & 18.8 & - & 23.1 & - & 12.5 & - & 12 & 10 & 60.4 & 48 & 58.8 & 49 \\
\hline \multirow{2}{*}{$\begin{array}{l}\text { (7) } a+b \text { is the } \\
\text { same as } b+a\end{array}$} & Absence & 一 & - & - & - & - & - & - & - & 9.1 & 6.1 & 9.1 & 4.5 \\
\hline & Presence & - & - & - & - & - & - & - & - & 12.5 & 18 & 17.6 & 24.5 \\
\hline \multirow{2}{*}{$\begin{array}{l}\text { (8) The same } \\
\text { addend and signs }\end{array}$} & Absence & 6.4 & - & 12.5 & 11.7 & - & - & - & - & - & - & - & - \\
\hline & Presence & - & - & - & 一 & - & - & - & - & - & - & - & - \\
\hline
\end{tabular}

${ }^{*} 1,1+N ; 2$, circles + numerals; 3 , numerical facts; 4 , numerical facts greater than ten.

\section{Compare Sums Task with the Result Present}

We observed that children used the same strategies as above with exception of the following ones: strategies in which children indicated that both the addends and the mathematical signs were the same for the two numerical additions (type 8 in Table 5), and strategies in which children maintained that the result for both operations was the same once they had done both sums (type 4). Likewise, as may be seen in Table 5, children from groups I and II obtained in general the same results as those for the compare sums task in absence of the result. Thus, the majority of these children employed strategies related to the addends (an average of $89.55 \%$ and $72.58 \%$ of the trials for groups I and II respectively). However, group III children preferred the strategy based on the result (an average of $54.05 \%$ of the trials), though we also observed a noticeable increase regarding the strategy in which they stated the commutative law (an average of $18.15 \%$ of the trials).

To summarize, our data are not in line with those of Baroody and Gannon (1984), since they found that in the commutativity task subjects focused implicitly or explicitly on the results of the problems. This difference may originate from their experimental procedures employed that forced children to focus on the outcome. On the contrary, our observations of children's behavior in groups I and II showed their tendency to center on the addends when they were asked to justify the equivalence of the operations. 
Moreover, a great deal of preschoolers who attained a successful performance in the compare sums task in absence of the result failed when the result was present. The reason could be that for the compare sums task in absence of the result the children accepted the equivalence because both numerical additions involved the same terms, but in presence of the result they rejected the equivalence since one of the operations included an extra term. In other words, they were carrying out comparisons at a strictly perceptual level. On the other hand, and according to the point defended by Baroody and Gannon (1984), older children registered an increase in the use of the strategy related to the result, because they relied on this sort of strategy when they retrieved the answer, and they relied on the strategy based on the addends when they had not yet learned that number fact.

Table 6

Percentages of the Strategies Employed in the Find the Unknown Addend Task

\begin{tabular}{lcccccccccccccc}
\hline & & \multicolumn{3}{c}{ Group I } & \multicolumn{1}{c}{ Group II } & \multicolumn{4}{c}{ Group III } \\
Strategy & & $1^{*}$ & 2 & 3 & 4 & 1 & 2 & 3 & 4 & 1 & 2 & 3 & 4 \\
\hline $\begin{array}{l}\text { (1) Reference to } \\
\text { the addends }\end{array}$ & Absence & 10.7 & - & 9.6 & 17.7 & - & 3 & 4.6 & 4.5 & 44.1 & 30.8 & 43.5 & 60.9 \\
& Presence & 5 & - & 27.3 & - & 18.2 & 19.2 & 36.4 & 35.3 & 5 & 12.5 & 9.5 & 10.5 \\
$\begin{array}{l}\text { (2) Reference to } \\
\text { the result }\end{array}$ & Absence & 21.4 & - & 26.9 & 23.5 & 42.9 & 24.2 & 53.8 & 40.9 & 4.4 & - & - & - \\
(3) a + b is the & Presence & 15 & - & 13.6 & 66.7 & 45.5 & 19.2 & 27.3 & 35.3 & 85 & 39.3 & 66.7 & 63.2 \\
same as b + a & Absence & - & - & - & - & 14.3 & 3 & 4.6 & 13.6 & 39.7 & 23.1 & 34.8 & 17.4 \\
(4) Copy & Presence & - & - & - & - & - & - & - & - & - & - & - & - \\
& Absence & 67.9 & 99.9 & 63.5 & 58.8 & 42.9 & 69.7 & 36.9 & 36.4 & 11.8 & 46.2 & 21.7 & 21.7 \\
(5) Count on & Absence & 80 & 87.5 & 59.1 & 33.3 & 36.4 & 61.7 & 27.3 & 29.4 & 10 & 32.2 & 14.3 & 10.5 \\
from a given & Presence & - & - & - & - & - & - & - & - & 4.5 & - & - & - & - \\
numeral & Pres & & & & - & - & - & - & 9.1 & - & - & 16.1 & 9.5 & 15.8 \\
\hline
\end{tabular}

${ }^{*} 1,1+N, 2$ circles + numerals; 3 , numerical facts; 4 , numerical facts greater than ten.

\section{Finding the Unknown Addend Task in Absence of Result}

The strategies involved in this task were quite similar to those selected for the compare sums task (see Table 6). More precisely, we categorized children's strategies into five types. First, those focusing on the addends (i.e., "because here there is a ... and here - the other pair - there isn't") (type 1 in Table 6); second, the strategies related to the result (i.e., "because $a+b$ are $c$ and to have the same here it has to be a") (type 2); third, those directly centered on the commutative law (i.e., " $4+6$ is the same as $6+4$, because the result is the same") (type 3); fourth, copying strategies (i.e., "I've seen it here", "It's written here") (type 4); and, fifth, the additive strategy of counting on: children first solved the operation in which both addends were present and, then wrote down the sum in the other addition, to end up by counting on from the known addend up to the result in this latter operation (type 5). This strategy, only shown by group II children in a low percentage of trials $(4.5 \%)$, indicated that they 
focused exclusively on the outcome, without concern for the addends, to determine the equivalence of the two additive operations. Afterwards, these children also justified the equivalence of the algorithms taking into account the outcome.

As may be observed in Table 6, preschoolers showed a marked preference for the use of copying strategies (an average of $72.53 \%$ of the trials), a behavioral tendency also registered for group II (an average of $46.46 \%$ of the trials), though these subjects quite frequently employed the strategy centered on the result (an average of $40.46 \%$ of the trials). With regard to older children, they selected above all the strategy related to the addends, the commutative strategy also being relevant (an average of $44.8 \%$ and $29.84 \%$ of the trials, respectively).

\section{Finding the Unknown Addend Task with the Result Present}

We found here the same strategies as above, with the exception of the strategy directly related to the commutative law (see Table 6). Furthermore, the preschoolers and many children from the first course of EGB (group II) selected the copying strategy (an average of $64.98 \%$ and $38.7 \%$ of the trials respectively). Nevertheless, in this last group children also applied the strategies related to the result and to the addends (an average of $31.79 \%$ and $27.24 \%$ of the trials, respectively). Finally, older children responded mainly on the basis of the result (an average of $63.52 \%$ of the trials).

\section{A Hypothetical Five-Step Model of Understanding Commutativity}

The lack of conclusive work showing the developmental levels that children go through to reach a full understanding of commutativity, the links between commutativity and other arithmetical abilities, etc., encourage us to propose, in a hypothetical form, a five step model of the development toward full understanding of commutativity. This model can orient and guide continued theoretical work and empirical research that are obviously necessary.

Thus, integrating the most relevant data, especially those related to children's strategies and errors, we suggest a sequence of levels in the acquisition and understanding of the commutative law of addition that starts from an "explicit non-equivalence between commuted pairs" to an "explicit addends order/result coordination".

(1) No equivalence: children reject the equivalence pointing out that the addends are reversed, that the outcomes are different, or answering with one of the terms in the problem. Thus, for these children a different addend order involves a different sum. Most children in our study pertaining to this level come from group I, some from group II, and almost none from group III (see Tables 2, 3 and 4). This level corresponds to the first level of Baroody and Gannon (1984).

(2) Perceptual equivalence: children admit the equivalence depending on the presence of exactly the same terms in the two pairs (see the copy strategies, or the strategies in which children point out that both the addends and the signs are the same in the two operations). In this case children seem to base the equivalence on a static and element by element comparison, disregarding the order of the addends. This pattern of behavior is very clear in Tables 5 and 6 and appears mainly among the preschoolers (a mean of 
$46.5 \%$ of the trials), less frequently in group II $(29.25 \%)$, and is seldom observed in children from group III $(13.89 \%)$.

(3) Computing result-based equivalence: children base their judgment on the equivalence of the outcomes. Thus, they need to solve one of the two pairs involved in the commutativity tasks before judging whether they are equivalent. So, they make use of the following strategies in the "compare sums" task: finding the same result by computing one addition (in the result present condition), and finding the same result by computing both pairs. With regard to the task of finding the unknown addend, the strategy of counting on is assigned to this level. In the task of comparing sums in absence of the result, children's behavior should consist in solving just one of the two operations and immediately accepting that both are equivalent, despite the fact that one of the operations remains undone. We have found little empirical evidence of this level in our data: $1.2 \%, 8.62 \%$, and $11.78 \%$ of the trials respectively for groups I, II and III. This level would correspond to Baroody and Gannon's (1984) protocommutativity.

(4) Practical equivalence: when children reach this level, they assert the equivalence of the terms without computing, by simply indicating that the addends or the outcomes are the same although they do not coordinate explicitly addends and outcomes. The strategies focussing on the addends are those in which children indicate that the addends are equal in the commuted pairs or that they are reversed (e.g., " 8 and 11 and the other - meaning the other addition - too, are the same numbers"). The mean percentages of trials corresponding to these strategies are as follows: $38.9 \%, 39.6 \%$, and $30 \%$ for groups I, II, and III respectively. When the strategies make reference to the result, children affirm that the result is the same without computing (e.g., "the two - pointing to the commuted pairs - add up to the same"). Our findings show that the mean percentages of trials corresponding to this kind of strategy are as follows: $13.06 \%, 20.2 \%$, and $30.8 \%$ respectively for groups I, II, and III.

(5) Formal commutativity: at this level children directly state the commutative law of addition, by co-ordinating explicitly addends and results. That is, they say that the result of adding $a+b$ and $b+a$ is the same. Contrary to what happens at the previous level, children make an explicit reference to the results and the addends of the additive operations in their explanations; so they state that $4+6$ is the same as $6+4$. Our data indicate that the strategies related to this level are more frequently displayed by children of the second course of EGB (a mean of $13.52 \%$ of the trials) than by children of the first course of EGB (a mean of $2.22 \%$ of the trials), while they are completely absent in the group of preschoolers. This level corresponds to level 3 proposed by Baroody and Gannon (1984).

Finally, the discussion concerning the unary and binary conceptions of addition and its relations with the commutativity knowledge lies well beyond the scope of the present work. The continuation of further research is necessary. However, it seems reasonable to suggest that a unary understanding of addition underlies the computing result-based equivalence. According to Weaver (1982) children accept the commutation of the addends, but not necessarily the equivalence of the outcomes. That may be the reason why some children need to add before admitting the equivalence. The next step, practical equivalence, implies a gain of knowledge about the irrelevance of the order (at least in some situations) and about the equivalence through experience so that children do not need to compute the result to affirm this equivalence, but they do not yet have 
a full understanding of commutativity. Besides, this implies a certain understanding of the part-part-whole relationship, without showing an explicit coordination between the addends and the outcomes. The full understanding of commutativity would correspond to the formal commutativity step, since children's reasoning is based on a binary conception of addition (Weaver, 1982). This conception allows for the coordination of addends and results, which is not possible with a unary conception.

Acknowledgements - The authors wish to thank the two anonymous referees and Oliva Lago for their suggestions.

\section{References}

Baroody, A. J. (1982). Are discovering commutativity and more economical strategies related? Problem Solving, 4, 1-2.

Baroody, A. J. (1984). More precisely defining and measuring the order-irrelevance principle. Journal of Experimental Child Psychology, 38, 33-41.

Baroody, A. J., \& Gannon, K. E. (1984). The development of the commutativity principle and economical addition strategies. Cognition and Instruction, 1, 321-339.

Baroody, A. J., \& Ginsburg, H. P. (1983). The effects of instruction on children's understanding of the "equal" sign. The Elementary School Journal, 84, 199-212.

Baroody, A. J., \& Ginsburg, H. P. (1986). The relationships between initial meaningful and mechanical knowledge of arithmetic. In J. Hiebert (Ed.), Conceptual and procedural knowledge: The case of mathematics (pp. 75-112). Hillsdale, NJ: Erlbaum.

Baroody, A. J., Ginsburg, H. P., \& Waxman, B. (1983). Children's use of mathematical structure. Journal for Research in Mathematics Education, 14, 156-168.

Behr, M., Erlwanger, S., \& Nichols, E. (1976). How children view equality sentences (PMDC Technical Report No. 3). Tallahassee: Florida State University. Reported by C. Kieran (1981).

Bermejo, V., \& Rodríguez, P. (1990). Relevancia de algunos factores en la solución de problemas aditivos. Investigaciones Psicológicas, 8, 23-41.

Bermejo, V., \& Rodríguez, P. (1991). Etapas en la adquisición de la propiedad conmutativa de la suma. I Congreso Internacional de Psicología y Educación. Madrid, Spain.

Bermejo, V., \& Rodríguez, P. (1992). Conceptual fundamentation of the commutative law of addition and its levels of acquisition. Abstracts from the fifth European conference on developmental psychology. Seville, Spain.

Bermejo, V., \& Rodríguez, P. (in press). Conceptualización de la operación aditiva y estrategias de solución. Investigaciones Psicológicas.

Briars, D. J., \& Larkin, J. H. (1984). An integrated model of skills in solving elementary word problems. Cognition and Instruction, 1, 245-296.

Carpenter, T. P. (1986). Conceptual knowledge as a foundation for procedural knowledge: Implications from research on the initial learning of arithmetic. In J. Hiebert (Ed.), Conceptual and procedural knowledge: The case of mathematics (pp. 113-132). Hillsdale, NJ: Erlbaum.

Carpenter, T. P., \& Moser, J. M. (1982). The development of addition and subtraction problem-solving skills. In T. P. Carpenter, J. M. Moser, \& T. Romberg (Eds.), Addition and subtraction: A cognitive perspective (pp. 9-24). Hillsdale, NJ: Erlbaum.

De Corte, E., \& Verschaffel, L. (1981). Children's solution processes in elementary arithmetic problems: Analysis and improvement. Journal of Educational Psychology, 73, 765-779.

Gelman, R., \& Gallistel, C. R. (1978). The child's understanding of number. Cambridge, MA: Harvard University Press.

Gelman, R., \& Meck, E. (1983). Preschoolers' counting: Principles before skill. Cognition, 13, 343-359.

Gelman, R., \& Meck, E. (1986). The notion of principle: The case of counting. In J. Hiebert (Ed.), Conceptual and procedural knowledge: The case of mathematics (pp. 29-57). Hillsdale, NJ: Erlbaum.

Ginsburg, H. (1982). Children's arithmetic. Austin, TX: PROED.

Hiebert, J. (1989). The struggle to link written symbols with understanding: An update. Arithmetic Teacher, 36, 38-44.

Kieran, C. (1981). Concepts associated with the equality symbol. Educational Studies in Mathematics, 12, $317-325$. 
Miller, K., Perlmutter, M., \& Keating, D. (1984). Cognitive arithmetic: Comparison of operations. Journal of Experimental Psychology: Learning, Memory, and Cognition, 10, 46-60.

Resnick, L. B. (1983). A developmental theory of number understanding. In H. Ginsburg (Ed.), The development of mathematical thinking (pp. 136-155). New York: Academic Press.

Resnick, L. B., \& Neches, R. (1984). Factors affecting individual differences in learning ability. In R. J. Sternberg (Ed.), Advances in the psychology of human intelligence (pp. 275-323). Hillsdale, NJ: Erlbaum.

Riley, M. S., Greeno, J. G., \& Heller, J. I. (1983). Development of children's problem-solving ability in arithmetic. In H. Ginsburg (Ed.), The development of mathematical thinking (pp. 153-196). New York: Academic Press.

Rodríguez, P. (1992). Análisis de los procesos cognitivos que conducen a la adquisición de la propiedad conmutativa. Madrid: Universidad Complutense.

Wagner, S., \& Walters, J. (1982). A longitudinal analysis of early number concepts: From numbers to number. In G. Forman (Ed.), Action and thought (pp. 137-161). New York: Academic Press.

Weaver, J. F. (1982). Interpretations of number operations and symbolic representations of addition and subtraction. In T. Carpenter, J. Moser, \& T. Romberg (Eds.), Addition and subtraction: A cognitive perspective (pp. 60-66). Hillsdale, NJ: Erlbaum. 